\title{
Clinical presentation, treatment, and prognosis of periocular and orbital amyloidosis in a university-based referral center
}

This article was published in the following Dove Press journal:

Clinical Ophthalmology

29 April 2013

Number of times this article has been viewed

Orapan Aryasit

Passorn Preechawai

Kanita Kayasut

Department of Ophthalmology, Faculty of Medicine, Prince of Songkla University, Hat Yai, Songkhla, Thailand
Correspondence: Orapan Aryasit

Department of Ophthalmology,

Faculty of Medicine, Prince

of Songkla University,

Hat Yai, Songkhla,

90110 Thailand

$\mathrm{Tel}+6674451380$

Fax +6674429619

Email all_or_none2278I@hotmail.com
Objective: The purpose was to present the demographic data, clinical presentation, and treatment options, and to evaluate prognosis, for periocular and orbital amyloidosis in patients at the Songklanagarind Hospital, Thailand.

Method: This was a retrospective study that reviewed the clinical records of six patients who were diagnosed with periocular and orbital amyloidosis between January 1, 2002 and December 31, 2011.

Results: The series included six patients (five female and one male). The mean age was 39.7 years (range 15-79 years). There were five cases of unilateral lesion and one case of bilateral lesion. The most common symptom was a mass lesion (83.3\%), followed by irritation $(66.7 \%)$, bloody tears $(16.7 \%)$, epiphora $(16.7 \%)$, eye pain $(16.7 \%)$, and ptosis $(16.7 \%)$. Five cases had periocular involvement and one case had orbital involvement. Five cases were investigated to rule out systemic amyloidosis, and no systemic involvement was found in these cases. The median duration of symptoms was 6 months, but the mean was 31 months. The main treatment option was surgical excision. The mean follow-up time was 41 months. There was disease progression in $20 \%$ of cases after definitive treatment.

Conclusion: Periocular and orbital amyloidosis presented with a variety of symptoms, depending on the location of the disease. A mass lesion was the most common symptom. The intent of the treatment modalities was to spare function.

Keywords: primary localized amyloidosis, eyelid, conjunctiva

\section{Introduction}

Amyloidosis is a heterogeneous group of diseases characterized by extracellular amyloid deposits in different organs. ${ }^{1}$ The clinical presentation can be classified by the clinicopathological features, the disease locations and magnitude of amyloid deposits. ${ }^{1}$ The gold standard of amyloid detection is the demonstration of apple-green birefringence on congo red staining. ${ }^{2}$ Sites of periocular and orbital amyloid deposit are the lacrimal gland, eyelid, conjunctiva, and ocular adnexa, and these are generally associated with primary localized diseases; however, all patients should be investigated to rule out systemic involvement. Amyloidosis is a cause of tissue destruction and is a progressive disease. ${ }^{2}$ Localized amyloidosis has no effect on survival. ${ }^{3}$ Because periocular and orbital amyloidosis is rare, the definitive diagnosis can be delayed, which could lead to disease progression. The clinical presentation depends on the location of the disease. Some research showed multiple myeloma to be associated with amyloidosis in systemic amyloidosis. ${ }^{4-6}$ To date, the largest reported series of periocular and orbital amyloidosis was of 24 patients (including seven cases with orbital involvement and 17 
cases with periocular involvement). ${ }^{7}$ We report an additional six patients with amyloidosis involving several locations: the eyelid, conjunctiva, lacrimal gland, and lacrimal punctum.

\section{Materials and methods}

This is a retrospective study that collected data from clinical records. Six patients were diagnosed with periocular and orbital amyloidosis between January 1, 2002 and December 31, 2011. The diagnosis of periocular and orbital amyloidosis was confirmed by tissue histopathology. We reviewed the clinical records of these patients: demographic data, the duration of the clinical presentation, location of the disease, the histopathologic result, treatment modalities, and outcome. We analyzed the data using open-source statistical software (Epicalc 2.13.2.2; R Foundation for Statistical Computing, Vienna, Austria).

\section{Results}

Our study had six patients, five female (83.3\%) and one male $(16.7 \%)$. The mean age was $39.7 \pm 23.3$ years, median age was 38.5 years, and the range of age was $15-79$ years. The mean duration of initial symptoms was 31 months, median time was 6 months, and the symptom duration range was 4 months to 11 years. The histopathology of all patients was reviewed. All cases were confirmed the diagnosis of amyloidosis by congo red stain with apple-green birefringence by polarized light. One 46-year-old woman had an eyelid mass of the left eye. Her histopathology showed amyloid deposition, appearing as amorphous eosinophilic extracellular substance in the stroma of the subepithelial area of the eyelid (Figure 1), and Congo red stain demonstrated orange-red deposits of amyloid (Figure 2).

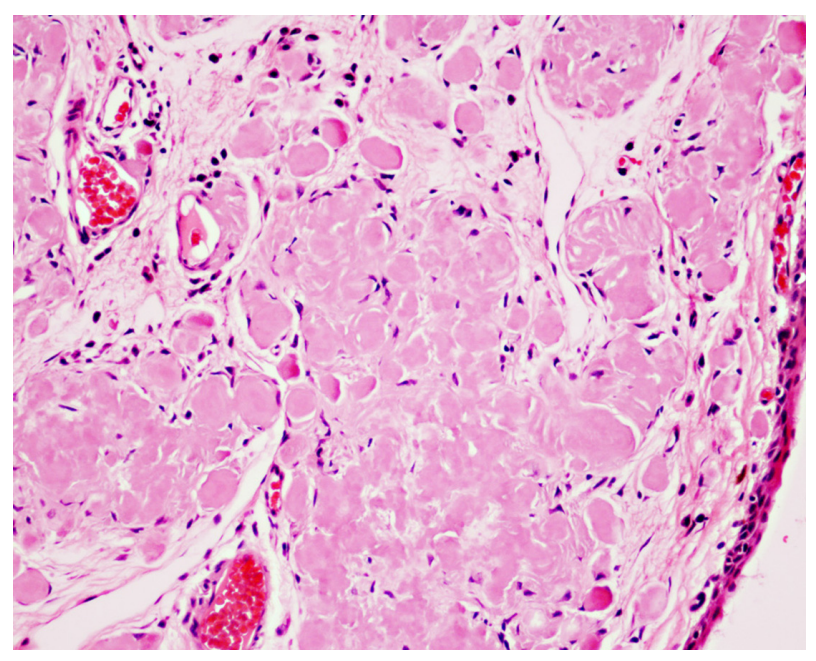

Figure I Amyloid deposition appearing as an amorphous, eosinophilic extracellular substance in the stroma of a subepithelial area of the eyelid.

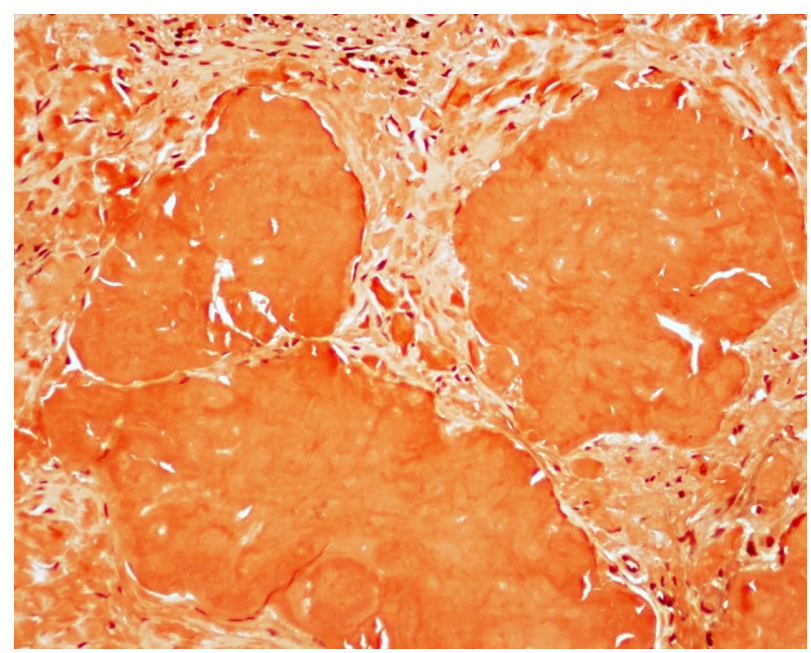

Figure 2 Congo red stain demonstrating orange-red deposits of amyloid.

The affected eye was the left eye in five cases, and in one case, both eyes were affected. All patients denied having a history of trauma. Five patients had no underlying diseases. One 79-year-old male, who had transitional cell carcinoma of the kidney postnephrectomy in 2007 and chronic obstructive pulmonary disease, had amyloidosis in the left punctum. Although the oculoplastic surgeon sent this patient for a systemic amyloidosis investigation, he did not visit an internist.

The visual acuity of the six patients was evaluated with the Early Treatment Diabetic Retinopathy Study (ETDRS) chart. ${ }^{8,9}$ It showed a 20/20 result in four patients, 20/25 in one patient, and 20/50 in one patient who had nuclear sclerosis. The patient data and details are recorded in Table 1.

The data describing the clinical presentations are summarized in Table 2 . The most common presentation was a mass lesion in the eyelid (four cases). Other presentations were lesions in the conjunctiva (two cases), lacrimal gland (one case), and the punctum (one case). Two of the patients had two sites of amyloidosis. We showed the clinical feature of conjunctival amyloidosis (Figure 3).

Five patients were sent for investigation of systemic involvement, but no evidence of systemic amyloidosis was found. The mean follow-up time was 41 months (range 11 to 106 months).

The treatment modalities depended on the location and/or symptoms of the disease. Some cases were diagnosed by incisional biopsy and also thus, treated. Symptoms such as ptosis were treated by surgical debulking, with levator resection. Out of five cases treated with definitive surgery, four patients were stable after treatment, and one patient had progression at the conjunctiva. Only one patient refused surgical excision, and so the disease progressed. 
Table I Patients' data and details of periocular and orbital amyloidosis

\begin{tabular}{|c|c|c|c|c|c|c|c|}
\hline Patient & Age & Sex & Eye & Symptoms and signs & Sites & Treatment & Outcome \\
\hline I & 47 & $\mathrm{~F}$ & LE & Mass, irritation, ptosis & $\begin{array}{l}\text { Eyelid, } \\
\text { conj }\end{array}$ & $\begin{array}{l}\text { Sx debulking, } \\
\text { levator resection }\end{array}$ & Stable \\
\hline 2 & 79 & $M$ & LE & Mass at punctum, epiphora & Punctum & Canaliculotomy & Stable \\
\hline 3 & 46 & $\mathrm{~F}$ & LE & Mass, irritation & $\begin{array}{l}\text { Eyelid } \\
\text { Lacrimal gland }\end{array}$ & Sx excision & $\begin{array}{l}\text { Progression } \\
\text { at conj. }\end{array}$ \\
\hline 4 & 20 & $\mathrm{~F}$ & LE & $\begin{array}{l}\text { Mass, irritation, bloody } \\
\text { tears }\end{array}$ & Eyelid & Sx excision & Stable \\
\hline 5 & 31 & $\mathrm{~F}$ & LE & Irritation, eye pain & Conj & Incisional biopsy & Progression \\
\hline 6 & 15 & $\mathrm{~F}$ & $\mathrm{BE}$ & Mass & Eyelids & Sx excision & Stable \\
\hline
\end{tabular}

Abbreviations: BE, both eyes; conj, conjunctiva; F, female; Lacrimal gl, Lacrimal gland; LE, left eye; M, male; Sx debulk, Surgical debulking; Sx excision, Surgical excision.

\section{Discussion}

In our study, we present a case series with periocular and orbital amyloidosis, which is a very rare disease. We collected the data of patients who were treated over a period of 10 years at the Songklanagarind Hospital.

According to a new classification, amyloidosis is categorized as localized or systemic. ${ }^{10,11}$ The origin of systemic amyloidosis is either hereditary or acquired. ${ }^{12,13}$ The common form of localized amyloidosis is associated with mucous membranes (for eg, conjunctiva). The most common form of local amyloidosis is caused by the local deposition of monoclonal immunoglobulin light chains by a usually benign B-cell or plasma-cell clone and is called localized amyloid light chain amyloidosis. ${ }^{7}$ Some types of amyloidosis are associated with cardiac, cerebral, or renal involvement, and so all cases of periocular and orbital amyloidosis are investigated for systemic involvement, although this is rare. In this study, five patients were worked up for systemic amyloidosis, and their results were negative.

Most of the periocular and orbital amyloid research has been reported in case reports of conjunctival amyloidosis. ${ }^{17,18}$ Conjunctival amyloidosis, which manifests as a yellow-pink hemorrhagic mass deep in the epithelium, is an uncommon condition. Six patients were diagnosed with conjunctival amyloidosis. There was no systemic involvement in the five patients. ${ }^{14} \mathrm{~A}$ case report with a 10 -year follow-up period

Table 2 Clinical presentation of periocular and orbital amyloidosis

\begin{tabular}{ll}
\hline Clinical presentation & Number of patients (\%) \\
\hline Mass lesion & $5(83.3 \%)$ \\
Eye irritation & $4(66.7 \%)$ \\
Bloody tears & $\mathrm{I}(16.7 \%)$ \\
Eye pain & $\mathrm{I}(16.7 \%)$ \\
Epiphora & $\mathrm{I}(16.7 \%)$ \\
Blepharoptosis & $\mathrm{I}(16.7 \%)$ \\
\hline
\end{tabular}

for primary localized conjunctival amyloidosis has shown no recurrence after excision was described by Demirci $\mathrm{H}$ et al. ${ }^{15}$ Eyelid amyloidosis manifests as unilateral ptosis due to localized amyloid in the levator muscle. ${ }^{16}$ Our study showed a case of amyloidosis of the lacrimal punctum, which is extremely rare and not previously documented in the literature.

The clinical presentation of periocular and orbital amyloidosis is different, in some cases, depending on the affected site. As a result, it is difficult to diagnose the disease of amyloidosis and some cases have had a delayed diagnosis and treatment. In our study, the mean duration of the initial symptoms was more than 2 years (range 4 months to 11 years). The most common symptom was a mass lesion (83.3\%), mimicking lymphoma. In a previous study, 24 patients were diagnosed with periocular and orbital amyloidosis. ${ }^{7}$ In that study, the most common signs and symptoms were a mass or tissue infiltration (95.8\%), and the mean duration of the initial clinical symptoms was 37 months. The data from both the large case series and our study were quite similar in clinical presentations, duration

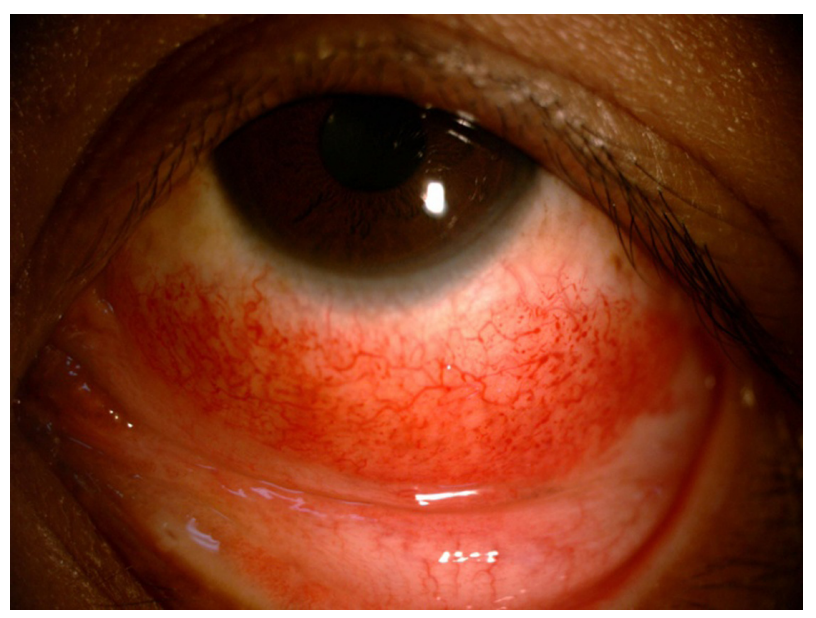

Figure 3 A 3 I-year-old woman who presented with a petechial hemorrhage above a conjunctival mass in the inferior area. 
of initial symptoms, and the follow-up time. The definitive diagnosis was confirmed from biopsied tissue, and the treatment modalities were chosen by the location of disease, functional defect, and cosmesis.

The treatment modalities of patients with primary localized amyloidosis depended on the location of the disease, so that surgical debulking ${ }^{7}$ or combined surgical debulking with external beam radiation was done for orbital amyloidosis, ${ }^{19}$ liquid nitrogen cryotherapy was administered for conjunctival amyloidosis, ${ }^{20}$ and in some case, the treatment was observation. ${ }^{7}$ In our series, one case was treated by incisional biopsy, three cases were treated by surgical excision, one case was treated using surgical debulking, with levator resection, after incisional biopsy for histopathology, and one case required canaliculotomy because the patient had canaliculitis and no epiphora after surgery. Two patients had disease progression. One of the two patients had progression because the patient was treated by incisional biopsy and the amyloidosis was not eradicated. The patient refused further surgery and decided to accept the potential harm. Following definitive surgery, one of five patients $(20 \%)$ in our study had disease progression, which is similar in rate to the larger case series that had a significant progression in $20.8 \%$ of patients. ${ }^{7}$

In Thailand, only one case of periocular and orbital amyloidosis was reported in $1995 .{ }^{21}$ We show the amyloidosis data of a retrospective descriptive case series, for which patient data were collected at Songklanagarind Hospital for the period from January 1, 2002 to December 31, 2011. Our study presented data of amyloidosis in Asian people. The criteria for an amyloid diagnosis were confirmed by histopathologic results. We showed the demographic data, the most common clinical presentation, duration of the clinical presentation, treatment modalities, and disease progression.

Since our study was limited in the number of amyloid patients, we could not statistically analyze it.

\section{Conclusion}

Periocular and orbital amyloidosis is an extremely uncommon disease, but it is important to confirm the diagnosis by histopathology and to perform a workup for systemic involvement in all cases. The prognoses of localized and systemic amyloidosis are different. Most of the time, periocular and orbital amyloidosis occur as a primary localized disease, which is treated by surgical debulking and observation.

\section{Disclosure}

The authors report no conflicts of interest in this work.

\section{References}

1. Rootman J. Degenerations and depositions. In: Rootman J, editor. Diseases of the Orbit: A Multidisciplinary Approach, 2nd ed. Philadelphia, PA: Lippincott Williams \& Wilkins; 2003:555-564.

2. Picken MM. Amyloidosis-where are we now and where are we heading? Arch Pathol Lab Med. 2010;134(4):545-551.

3. Naxer S, Behnes CL, Schittkowski MP. Amyloidosis - a rare differential diagnosis of an orbital tumour. Klin Monbl Augenheilkd. 2011;228(6): 555-564. German.

4. Lee HJ, Chang SE, Lee MW, Choi JH, Moon KC. Systemic amyloidosis associated with multiple myeloma presenting as periorbital purpura. J Dermatol. 2008;35(6):371-372.

5. Goshe JM, Schoenfield L, Emch T, Singh AD. Myeloma-associated orbital amyloidosis. Orbit. 2010;29(5):274-277.

6. Brown G, Shapeero LG, Weiss BM, Roschewski M. Multiple myeloma with lacrimal gland amyloidosis and sarcoidosis. Am J Hematol. 2010;85(7):506-509.

7. Leibovitch I, Selva D, Goldberg RA, et al. Periocular and orbital amyloidosis: clinical characteristics, management, and outcome. Ophthalmology. 2006;113(9):1657-1664.

8. Vanden Bosch ME, Wall M. Visual acuity scored by the letter-by-letter or probit methods has lower retest variability than the line assignment method. Eye (Lond). 1997;11:411-7.

9. Rosser DA, Cousens SN, Murdoch IE, Fitzke FW, Laidlaw DA. How sensitive to clinical change are ETDRS $\log$ MAR visual acuity measurements?. Invest Ophthalmol Vis Sci. 2003;44:3278-81.

10. Westermark P, Benson MD, Buxbaum JN; Nomenclature Committee of the International Society of Amyloidosis. Amyloid: toward terminology clarification. Report from the Nomenclature Committee of the International Society of Amyloidosis. Amyloid. 2005;12(1):1-4.

11. Pepys MB. Amyloidosis. Annu Rev Med. 2006;57:223-241.

12. Buxbaum JN. The systemic amyloidoses. Curr Opin Rheumatol. 2004;16(1):67-75.

13. Merlini G, Westermark P. The systemic amyloidoses: clearer understanding of the molecular mechanisms offers hope for more effective therapies. J Intern Med. 2004;255(2):159-178.

14. Demirci H, Shields CL, Eagle RC Jr, Shields JA. Conjunctival amyloidosis: report of six cases and review of the literature. Surv Ophthalmol. 2006;51(4):419-433.

15. Mesa-Gutiérrez JC, Huguet TM, Garcia NB, Ginebreda JA. Primary localized conjunctival amyloidosis: A case report with a ten-year follow-up period. Clin Ophthalmol. 2008;2(3):685-687.

16. Dithmar S, Linke RP, Kolling G, Völcker HE, Helmke B. Ptosis from localized A-lambda-amyloid deposits in the levator palpebrae muscle. Ophthalmology. 2004;111(5):1043-1047.

17. Cheong-Leen R. Primary localised conjunctival amyloidosis presenting as subconjunctival haemorrhage. Eye (Lond). 2001;15(Pt 5): 679-680.

18. Biewend ML, Menke DM, Calamia KT. The spectrum of localized amyloidosis: a case series of 20 patients and review of the literature. Amyloid. 2006;13(3):135-142.

19. Khaira M, Mutamba A, Meligonis G, Rose GE, Plowman PN, O'Donnell $\mathrm{H}$. The use of radiotherapy for the treatment of localized orbital amyloidosis. Orbit. 2008;27(6):432-437.

20. Fraunfelder FW. Liquid nitrogen cryotherapy for conjunctival amyloidosis. Arch Ophthalmol. 2009;127(5):645-648.

21. Tantachamroon T, Leeangulstean P, Patigulsila D, Aiumtrakul P, Attasiri C. Orbital amyloidoma (isolated amyloidosis): a case report. J Med Assoc Thai. 1995;78(7):374-378. 
Clinical Ophthalmology

\section{Publish your work in this journal}

Clinical Ophthalmology is an international, peer-reviewed journal covering all subspecialties within ophthalmology. Key topics include: Optometry; Visual science; Pharmacology and drug therapy in eye diseases; Basic Sciences; Primary and Secondary eye care; Patien Safety and Quality of Care Improvements. This journal is indexed on

PubMed Central and CAS, and is the official journal of The Society of Clinical Ophthalmology (SCO). The manuscript management system is completely online and includes a very quick and fair peer-review system, which is all easy to use. Visit http://www.dovepress.com/ testimonials.php to read real quotes from published authors. 